\title{
Dietary Methionine Improves the European Seabass (Dicentrarchus labrax) Immune Status, Inflammatory Response, and Disease Resistance
}

\section{OPEN ACCESS}

Edited by: Alexander G. Haslberger, Universität Wien, Austria

Reviewed by:

Zhonghai Yan,

Columbia University, United States Zhuoran Yin,

Harvard Medical School,

United States

*Correspondence:

Marina Machado

mcasimiro@ciimar.up.pt

Benjamín Costas

bcostas@ciimar.up.pt

Specialty section:

This article was submitted to Nutritional Immunology,

a section of the journal

Frontiers in Immunology

Received: 04 September 2018

Accepted: 29 October 2018

Published: 20 November 2018

Citation:

Machado M, Azeredo R, Fontinha F, Fernández-Boo S, Conceição LEC, Dias J and Costas B (2018) Dietary Methionine Improves the European

Seabass (Dicentrarchus labrax)

Immune Status, Inflammatory Response, and Disease Resistance. Front. Immunol. 9:2672.

doi: 10.3389/fimmu.2018.02672

\author{
Marina Machado ${ }^{1,2,3,4 *}$, Rita Azeredo ${ }^{1,3}$, Filipa Fontinha ${ }^{1,3}$, Sergio Fernández-Boo ${ }^{1}$, \\ Luis E. C. Conceição ${ }^{5}$, Jorge Dias ${ }^{5}$ and Benjamín Costas ${ }^{1,3 *}$
}

${ }^{1}$ Centro Interdisciplinar de Investigação Marinha e Ambiental, Matosinhos, Portugal, ${ }^{2}$ Instituto de Investigação e Inovação em Saúde, Universidade do Porto, Porto, Portugal, ${ }^{3}$ Instituto de Ciências Biomédicas Abel Salazar, Universidade do Porto, Porto, Portugal, ${ }^{4}$ Instituto de Biologia Molecular e Celular, Universidade do Porto, Porto, Portugal, ${ }^{5}$ Sparos Lda, Olhão, Portugal

Methionine presents a pivotal role in the regulation of many cellular events with crucial impact on the immune system, such as in processes involved in the control of inflammation and polyamines synthesis. Accordingly, the present study aimed to assess the modulatory effects of dietary methionine on the European seabass (Dicentrarchus labrax) immune status, inflammatory response and disease resistance to Photobacterium damselae subsp. piscicida (Phdp). For this purpose, fish were randomly distributed in three independent groups (three replicates per group) and each was fed the corresponding diet: a control diet (CTRL) formulated to meet the established amino acid requirements for the species; a diet supplemented with methionine at $0.5 \%$ of feed weight relative to the CTRL diet $(8.2 \%$ of methionine concentration above CTRL); and one supplemented with methionine at $1 \%$ of feed weight to the CTRL diet (11.8\% of methionine concentration above CTRL). To evaluate the immune status of fish fed with each of the diets before being submitted to bacterial infection fish were sampled from each group at 2 and 4 weeks after the beginning of feeding. Non-sampled fish were injected intraperitoneally with Phdp $\left(5 \times 10^{3} \mathrm{cfu} / \mathrm{fish}\right)$ at 4 weeks after initiation of feeding and the inflammatory response (at 4, 24, and $48 \mathrm{~h}$ post-infection) and survival (lasting 21 days post-infection) evaluated. Fish hematological profile, peripheral cell dynamics, plasma humoral immune parameters, leucocyte migration to the inflammatory focus and head-kidney gene expression were evaluated. Results show that methionine dietary supplementation improves seabass cellular immune status without evidence of activation of pro-inflammatory mechanisms. Additionally, the observed enhanced immune status provided by methionine supplementation translated into an improved immune response to infection, as higher cellular differentiation/proliferation and recruitment to the inflammatory focus, improved plasma humoral immune parameters and modulation of key immune-related genes was observed. Lastly, after a bacterial challenge, higher survival was observed in fish fed supplemented diets, ultimately corroborating the positive effect of methionine administration for 4 weeks in the cellular immune status.

Keywords: amino acids, cell proliferation, inflammation, immunostimulation, fish, nutraceutics 


\section{INTRODUCTION}

A dependency of the immune system upon the availability of amino acids (AA) has been associated to their role as signaling molecules essential for cellular function as reviewed in (1-4), but also as methyl group donors and precursors of physiological important molecules, such as hormones, bioactive amines, enzymes, neurotransmitters and nitric oxide. Several studies have reported that AA deficiency reduces their plasma concentration, ultimately compromising the immune system repertoire $(5,6)$. In fact, AA requirements may increase as a direct consequence of metabolic changes associated with inflammation and infection (7). Methionine is an example of an indispensable AA with a recognized role in the immune system and its dietary supplementation proved to enhance mammalian host immunity (8). By generating S-adenosylmethionine (SAM), methionine is a methyl group donor that participates in the methylation of DNA, ultimately influencing gene expression (8). Additionally, methionine takes part on the polyamine (i.e., spermidine and spermine) biosynthesis through the aminopropylation pathway, where decarboxylated SAM successively adds aminopropane to the forming polyamines, required for cell proliferation (9). During the transsulfuration pathway, methionine is also precursor of cysteine, one of the three glutathione (GSH) elements, a molecule involved in scavenging free radicals, hence protecting cells from oxidative stress during inflammation (1). Methionine also plays a pivotal role in processes responsible for the control of inflammation and apoptosis, such as protein ubiquitination and autophagy (10). By inducing SAMmediated methylation, methionine has been shown to inhibit autophagy and promote growth in yeast (11). In fact, methionine and its downstream metabolite SAM are responsible for autophagy modulation (12). As a result, and knowing that the ideal inflammatory response is rapid, yet specific and self-limiting (13), methionine presents an important potential as immunomodulator during infection. Still, further in-depth studies are needed to understand the immune mechanisms that this particular AA is activating before and after infection episodes.

Methionine dietary immunomodulation also adds a practical perspective to modern animal production. For instance, the importance of methionine as a nutraceutical supplement to control enteric processes and oxidative stress in mammals has been recently reviewed (14). Moreover, Bunchasak (15) and Jankowski et al. (16) reviewed the many beneficial effects of dietary methionine (and other sulfur-containig AA) on poultry immune mechanisms and its use on poultry industry.

However, the role of methionine as an immunomodulatory additive in aquafeeds still needs to be explored so to improve sustainability and fish welfare in fish farming. Recent studies showed that methionine supplementation increase European seabass (Dicentrarchus labrax) cellular immune status as well as immune response to an inflammatory insult with UVinactivated Photobacterium damselae subsp. piscicida (Phdp) (17). An increased peripheral leucocytes concentration was also observed in juvenile Jian carp (Cyprinus carpio var. Jian) after being fed graded levels of methionine hydroxy analog, a synthetic methionine source, resulting in increased survival rate and stronger humoral and cellular response after injection with Aeromonas hydrophila (18). Likewise, Tang and co-workers (19) observed an increase in plasma lysozyme activity, complement factors and IgM of Jian carp given dietary methionine supplementation during 8 weeks. Therefore, dietary methionine also seems to be an important nutritional additive for fish health management. The main goal of the present study was to gather evidence on the specific role of methionine orchestrating the European seabass immune response before and after a $P h d p$ infection.

\section{MATERIALS AND METHODS}

\section{Experimental Design}

European seabass juveniles were acquired to a certificated hatchery (MARESA, Spain) and maintained in quarantine for 2 weeks at the Instituto de Investigação e Inovação em Saúde (i3S; University of Porto, Portugal) fish holding facilities under the culture conditions described below. After this period, fish were weighed (Table 4) and randomly distributed into 9 tanks (200 l; 3 groups with 3 replicates of 50 fish each) of a recirculation seawater system in which $\mathrm{O}_{2}$ saturation $(7.38 \pm 0.01 \mathrm{mg} / \mathrm{l})$, salinity (35 ppt) and photoperiod ( $10 \mathrm{~h}$ dark: $14 \mathrm{~h}$ light) were kept unchanged throughout the experiment (Figure 1). The temperature was maintained at $20 \pm 0.5^{\circ} \mathrm{C}$ until the time the bacterial infection was carried out (4 weeks after feeding with the test diets), where it was increased to $24 \pm 0.5^{\circ} \mathrm{C}$ until de end of the experiment so as to mimic the temperature increase which typically triggers piscine outbreaks. Ammonium and nitrite levels were kept below 0.025 and $0.3 \mathrm{mg}^{-1}$, respectively.

After 1 week, during which fish were all fed with the commercial diet with which they were being fed previously, the experiment was started by feeding of each group with the respective feed 3 times a day at an average ration of $2.5 \%$ biomass per day (daily adjusted $\pm 0.5 \%$ based on the assessment of the non-consumed feed): (i) one group was fed a control diet (CTRL); (ii) another group was fed a diet supplemented with $0.5 \%$ methionine of feed weight to the CTRL diet (MET0.5); and finally, (iii) another group was fed a diet supplemented with $1 \%$ methionine of feed weight to the CTRL diet (MET1).

At 2 and 4 weeks after feeding the test diets, 36 fish from each group (12 per replicate) were euthanized by an overdose of anesthetic (2-phenoxyethanol; Merck, ref. 807291, Germany), weighed, and collected blood and head kidney samples. Also at 4 weeks, fish that were not sampled (78 per group, 26 per replicate) were infected intraperitoneally (i.p.) with $100 \mu \mathrm{l}$ of a $P h d p$ suspension $\left(5 \times 10^{4} \mathrm{cfu} \mathrm{ml}^{-1}\right)$. Of these, 60 fish per group $(20$ per replicate) were placed back in their tanks, feed replenished according to the previous regimen and mortality recorded for 3 weeks and the relative percentage survival (RPS) calculated. After euthanasia of the moribund fish, the animals were weighed and the presence of Phdp in the head-kidney checked by growing on TSA-2 plates. The remaining infected fish (6 per group, 3 per replicate) were re-allocated in a similar recirculation system (Temperature: $24 \pm 0.5^{\circ} \mathrm{C}$; Salinity: $35 \mathrm{ppt}$; Photoperiod: $10 \mathrm{~h}$ dark: $14 \mathrm{~h}$ light) according to dietary treatment and 6 fish per 


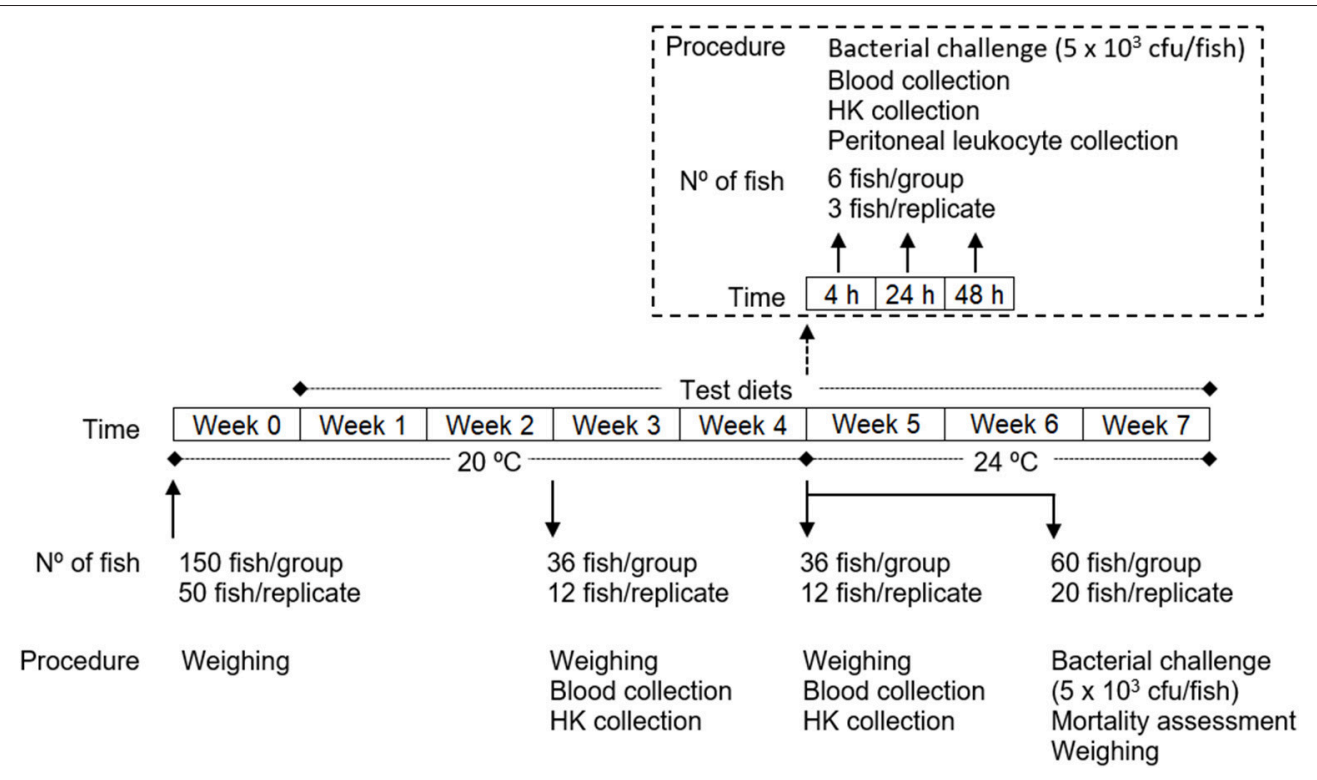

FIGURE 1 | Experimental design.

group were euthanized at 4,24 , and $48 \mathrm{~h}$ post-infection (timecourse) and blood, head-kidney and peritoneal exudates sampled from each fish, to investigate the immunomodulatory effect of the diets during the initial inflammatory response to $P h d p$.

The experiments were approved by the i3S Animal Welfare Committee and carried out in a registered installation (license number 0421/000/000/2018). Experiments were performed by trained scientists in full compliance with national rules and following the European Directive 2010/63/EU of the European Parliament and the European Union Council on the protection of animals used for scientific purposes.

\section{Experimental Diets}

The 3 diets (Table 1) were formulated and manufactured by Sparos Lda (Olhão, Portugal). The CTRL diet was formulated to include an indispensable AA profile meeting the ideal pattern estimated for European seabass (20). According to results from previsous works $(17,21)$ two other diets were formulated (MET 0.5 and MET 1, respectively) to be identical to the CTRL but supplemented with DL-Methionine at 0.5 or $1 \%$ of feed weight, at the expenses of wheat gluten and wheat meal. After AA analysis the percentage of methionine in relation to the total AA amount was of $2.6 \%$ for CTRL and 2.8 and $3.2 \%$ for MET 0.5 and MET 1, respectively, presenting these diets 8.2 and $11.8 \%$ more methionine than CTRL.

Main ingredients were ground (below $250 \mu \mathrm{m}$ ) in a micropulverizer hammer mill (SH1; Hosokawa Micron, B.V., Doetinchem, The Netherlands). Powder ingredients and oils were then mixed according to the target formulation in a paddle mixer (RM90; Mainca, S.L., Granollers, Spain). All diets were manufactured by temperature-controlled extrusion (pellet sizes: $1.5 \mathrm{~mm}$ ) by means of a low-shear extruder (P55; Italplast, S.r.l., Parma, Italy). Upon extrusion, all feed batches were dried in a convection oven (OP 750-UF; LTE Scientifics, Oldham, UK) for $4 \mathrm{~h}$ at $45^{\circ} \mathrm{C}$. Formulation of experimental diets is presented in Table 1. Proximate composition analysis was conducted by the following methods: dry matter, by drying at $105^{\circ} \mathrm{C}$ for $24 \mathrm{~h}$; ash, by combustion at $550^{\circ} \mathrm{C}$ for $12 \mathrm{~h}$; crude protein $(N \times 6.25)$, by a flash combustion technique followed by gas chromatographic separation and thermal conductivity detection (LECO FP428); fat, after petroleum ether extraction, by the Soxhlet method; total phosphorus, according to the ISO/DIS 6491 method, using the vanado-molybdate reagent; gross energy, in an adiabatic bomb calorimeter (IKA).

Diets were analyzed for total AA content. Diet samples were hydrolysed in $6 \mathrm{M} \mathrm{HCl}$ at $116^{\circ} \mathrm{C}$ for $2 \mathrm{~h}$ in nitrogen-flushed glass vials. Samples were then pre-column derivatised with Waters AccQ Fluor Reagent (6-aminoquinolyl-N-hydroxysuccinimidyl carbamate) using the AccQ Tag method (Waters, USA). Analyses were done by ultra-high performance liquid chromatography (UPLC) in a Waters reversed-phase AA analysis system, using norvaline as an internal standard. During acid hydrolysis asparagine is converted to aspartate and glutamine to glutamate, so the reported values for these AA represent the sum of the respective amine and acid. Since it is partially destroyed by acid hydrolysis, tryptophan was not determined. The resultant peaks were analyzed with EMPOWER software (Waters, USA). The AA profile of the experimental diets and the relative percentage of methionine supplementation is presented in Table 2 .

\section{Collection of Blood, Head Kidney, and Peritoneal Exudates \\ Blood Collection}

Blood was collected from the caudal vein using heparinized syringes one part being used for hematological analysis and the remainder centrifuged at $10,000 \times \mathrm{g} 10 \mathrm{~min}$ at $4^{\circ} \mathrm{C}$ and the 
TABLE 1 | Ingredient and chemical composition of the experimental diets.

\begin{tabular}{|c|c|c|c|}
\hline Ingredients & CTRL & $\begin{array}{c}\text { MET } 0.5 \\
\%\end{array}$ & MET 1 \\
\hline $\begin{array}{l}\text { Fishmeal LT70 (South } \\
\text { American) }^{1}\end{array}$ & 11.00 & 11.00 & 11.00 \\
\hline Fishmeal $60^{2}$ & 17.00 & 17.00 & 17.00 \\
\hline Soy protein concentrate ${ }^{3}$ & 12.00 & 12.00 & 12.00 \\
\hline Wheat gluten ${ }^{4}$ & 8.00 & 7.70 & 7.40 \\
\hline Corn glúten ${ }^{5}$ & 4.00 & 4.00 & 4.00 \\
\hline Soybean meal $48^{6}$ & 14.00 & 14.00 & 14.00 \\
\hline Rapeseed meal $^{7}$ & 6.00 & 6.00 & 6.00 \\
\hline Wheat meal ${ }^{8}$ & 10.00 & 9.80 & 9.60 \\
\hline Fish oil ${ }^{9}$ & 8.50 & 8.50 & 8.50 \\
\hline Rapeseed oil ${ }^{10}$ & 5.00 & 5.00 & 5.00 \\
\hline $\begin{array}{l}\text { Vitamin and mineral } \\
\text { premix }{ }^{11}\end{array}$ & 1.00 & 1.00 & 1.00 \\
\hline Brewer's yeast ${ }^{12}$ & 3.00 & 3.00 & 3.00 \\
\hline Soy lecithin ${ }^{13}$ & 0.50 & 0.50 & 0.50 \\
\hline DL-Methionine ${ }^{14}$ & - & 0.50 & 1.00 \\
\hline Total & 100 & 100 & 100 \\
\hline Pellet size, mm & 1.50 & 1.50 & 1.50 \\
\hline \multicolumn{4}{|c|}{ PROXIMATE ANALYSES (\% DRY WEIGHT) } \\
\hline Dry matter (g/100 g) & 5.20 & 5.54 & 5.09 \\
\hline Protein (g/100 g) & 45.83 & 45.62 & 46.25 \\
\hline Fat $(g / 100 \mathrm{~g})$ & 18.80 & 19.00 & 18.10 \\
\hline Ash (g/100 g) & 7.74 & 7.58 & 7.81 \\
\hline Energy $(\mathrm{kJ} / \mathrm{g})$ & 22.48 & 22.70 & 22.55 \\
\hline
\end{tabular}

${ }^{1}$ LT70 steam dried, $70.7 \%$ crude protein (CP), 8.1\% crude fat (CF), Pesquera Diamante, Peru.

${ }^{2}$ COFACO 60: $62.3 \%$ CP, 8.4\% CF, COFACO, Portugal.

${ }^{3}$ Soycomil P: $63 \%$ CP, 0.8\% CF, ADM, The Netherlands.

${ }^{4}$ VITAL: $83.7 \%$ CP, $1.6 \%$ CF, ROQUETTE Frères, France.

${ }^{5}$ Corn gluten meal: $61 \%$ CP, $6 \%$ CF, COPAM, Portugal.

${ }^{6}$ Dehulled solvent extracted soybean meal: $47 \%$ CP, $2.6 \%$ CF, CARGILL, Spain.

${ }^{7}$ Defatted rapeseed meal: $34 \%$ CP, 2\% CF, Premix Lda, Portugal.

${ }^{8}$ Wheat meal: $10.2 \%$ CP; $1.2 \%$ CF, Casa Lanchinha, Portugal.

${ }^{9}$ SAVINOR UTS, Portugal.

${ }^{10}$ Henry Lamotte Oils GmbH, Germany.

${ }^{11} 20$ PREMIX Lda, Portugal: Vitamins (IU or $\mathrm{mg} / \mathrm{kg}$ diet): DL-alpha tocopherol acetate, $100 \mathrm{mg}$; sodium menadione bisulphate, $25 \mathrm{mg}$; retinyl acetate, 20,000 IU; DL-cholecalciferol, 2,000 IU; thiamin, $30 \mathrm{mg}$; riboflavin, $30 \mathrm{mg}$; pyridoxine, $20 \mathrm{mg}$; cyanocobalamin, $0.1 \mathrm{mg}$; nicotinic acid, $200 \mathrm{mg}$; folic acid, $15 \mathrm{mg}$; ascorbic acid, $500 \mathrm{mg}$; inositol, $500 \mathrm{mg}$; biotin, 3 mg; calcium panthotenate, $100 \mathrm{mg}$; choline chloride, 1,000 mg, betaine, $500 \mathrm{mg}$. Minerals (g or mg/kg diet): copper sulfate, $9 \mathrm{mg}$; ferric sulfate, $6 \mathrm{mg}$; potassium iodide, $0.5 \mathrm{mg}$; manganese oxide, $9.6 \mathrm{mg}$; sodium selenite, $0.01 \mathrm{mg}$; zinc sulfate, $7.5 \mathrm{mg}$; sodium chloride, $400 \mathrm{mg}$; excipient wheat middlings.

12 PREMIX Lda, Portugal.

${ }^{13}$ Lecico P70OIPM, LECICO GmbH, Germany.

14 DL-Methionine for Aquaculture: 99\% Methionine, Evonik Nutrition \& Care GmbH, Germany.

plasma collected, frozen on dry ice and stored at $-80^{\circ} \mathrm{C}$ for evaluating innate humoral immune response parameters. Of the fish sampled at 2 ( 36 fish per group; 12 per replicate) and at 4 (36 fish per group; 12 per replicate) weeks, 9 fish from each group (3 per replicate) were used per time point for the hematological analysis. For the assessment of innate humoral immune response,
TABLE 2 | Amino acid composition of experimental diets.

\begin{tabular}{lrcr}
\hline Amino acids & CTRL & $\begin{array}{c}\text { MET 0.5 } \\
\text { mg AA/g DW diet }\end{array}$ & MET 1 \\
\hline Methionine & & 11.8 & 13.2 \\
Arginine & 10.8 & 39.6 & 39.3 \\
Histidine & 39.5 & 11.9 & 11.7 \\
Lysine & 11.9 & 27.8 & 28.4 \\
Threonine & 27.9 & 16.8 & 17.5 \\
Isoleucine & 17.4 & 16.1 & 15.8 \\
Leucine & 15.9 & 32.5 & 32.3 \\
Valine & 32.3 & 21.0 & 20.3 \\
Phenylalanine & 20.1 & 22.7 & 22.4 \\
Cysteine & 22.4 & 3.1 & 3.0 \\
Tyrosine & 3.1 & 16.0 & 15.9 \\
Aspartic acid + Asparagine & 16.0 & 32.6 & 32.5 \\
Glutamic acid + Glutamine & 32.2 & 71.0 & 70.3 \\
Alanine & 70.6 & 21.3 & 22.0 \\
Glycine & 22.0 & 22.4 & 23.4 \\
Proline & 23.0 & 27.4 & 26.4 \\
Serine & 26.7 & 17.3 & 16.9 \\
Taurine & 17.8 & 1.2 & 1.2 \\
\hline
\end{tabular}

Tryptophan was not analyzed.

plasma from all sampled fish were used, although the plasma was pooled from every 3 individuals (12 pools per treatment).

Of the fish sampled at 4, 24, and $48 \mathrm{~h}$ after bacterial infection (6 fish per group; 3 per replicate) the hematological analysis and the evaluation of the innate humoral immune response parameters were performed for each individual.

\section{Head-Kidney Collection}

Head-kidneys were also harvested from the 9 fish sampled at 2 and 4 weeks and used for blood collection and hematological analysis. Likewise, the head-kidneys of all fish sampled at 4, 24 , and $48 \mathrm{~h}$ after infection were collected. After harvesting, the kidneys were immediately frozen on dry ice and stored at $-80^{\circ} \mathrm{C}$ until processed for gene expression analysis.

\section{Peritoneal Exudates Collection}

Peritoneal cells were only collected from fish sampled at 4,24, and $48 \mathrm{~h}$ post-infection (time-course), according to the procedure described by Costas et al. (22). Briefly, following fish anesthesia and bleeding by the caudal vessel, $5 \mathrm{ml}$ of cold Hank's balanced salt solution (HBSS) supplemented with 30 units heparin $\mathrm{ml}^{-1}$ was injected into the peritoneal cavity. The peritoneal area was then slightly massaged in order to disperse peritoneal cells in the injected HBSS. The i.p. injected HBSS containing suspended cells were collected and total peritoneal leucocytes counts were performed with a hemocytometer.

\section{Analysis of Hematological Parameters}

The hematological profile was conducted according to Machado et al. (17) and comprised the total white (WBC) and red (RBC) blood cells counts, as well as haematocrit $(\mathrm{Ht})$ 
and hemoglobin (Hb; SPINREACT kit, ref. 1001230, Spain) assessments. Afterwards, the mean corpuscular volume (MCV), mean corpuscular hemoglobin $(\mathrm{MCH})$ and mean corpuscular hemoglobin concentration (MCHC) were also calculated (17). Ht was not assessed in fish sampled at 4, 24, and $48 \mathrm{~h}$ post-infection.

Immediately after blood collection, blood smears were performed from homogenized blood and air dried. After fixation with formol-ethanol (10 of $37 \%$ formaldehyde in absolute ethanol) detection of peroxidase was carried out as described by Afonso et al. (23) in order to facilitate identification of neutrophils. Blood smears were then stained with Wright's stain (Haemacolor; Merck) Slides were examined $(1,000 \times)$, and at least 200 leucocytes were counted and classified as thrombocytes, lymphocytes, monocytes and neutrophils. Absolute value $\left(\times 10^{4}\right.$ $\mathrm{ml}^{-1}$ ) of each cell type was calculated according to the total blood WBC count.

\section{Analysis of Innate Immune Response Parameters Lysozyme Activity}

Lysozyme activity was measured using a turbidimetric assay as described by Costas et al. (22). A solution of Micrococcus lysodeikticus $\left(0.5 \mathrm{mg} \mathrm{ml}^{-1}, 0.05 \mathrm{M}\right.$ sodium phosphate buffer, $\mathrm{pH}$ 6.2) was prepared. In triplicates, $15 \mu \mathrm{l}$ of plasma was added to a microplate and $250 \mu \mathrm{l}$ of the above suspension were pipetted to give a final volume of $265 \mu \mathrm{l}$. The reaction was carried out at $25^{\circ} \mathrm{C}$ and the absorbance $(450 \mathrm{~nm})$ was measured after 0.5 and $4.5 \mathrm{~min}$ in a Synergy HT microplate reader. Serial diluted, lyophilized hen egg white lysozyme (Sigma) in sodium phosphate buffer $(0.05 \mathrm{M}$, $\mathrm{pH}$ 6.2), was used to develop a standard curve. The amount of lysozyme in the sample was calculated using the formula of the standard curve.

\section{Peroxidase Activity}

Total peroxidase activity in plasma was measured following the procedure described by Quade and Roth (24). In triplicates, 15 $\mu l$ of plasma was diluted with $135 \mu$ l of HBSS without $\mathrm{Ca}^{+2}$ and $\mathrm{Mg}^{+2}$ in flat-bottomed 96 -well plates. Then, $50 \mu \mathrm{l}$ of $20 \mathrm{mM}$ $3,3^{\prime}, 5,5^{\prime}$-tetramethylbenzidine hydrochloride (TMB; Sigma) and $50 \mu \mathrm{l}$ of $5 \mathrm{mM} \mathrm{H}_{2} \mathrm{O}_{2}$ were added. After $2 \mathrm{~min}$, the color-change reaction was stopped by adding $50 \mu \mathrm{l}$ of $2 \mathrm{M}$ sulphuric acid and the optical density was read at $450 \mathrm{~nm}$ in a Synergy HT microplate reader. Wells without plasma were used as blanks. The peroxidase activity (units $\mathrm{ml}^{-1}$ plasma) was determined by defining one unit of peroxidase as that which produces an absorbance change of 1 OD.

\section{Bactericidal Activity}

The bactericidal activity assay was performed using Phdp strain PP3. Bacteria were cultured in tryptic soy broth (TSB) (Difco Laboratories) supplemented with $\mathrm{NaCl}$ to a final concentration of $2 \%(\mathrm{w} / \mathrm{v})(\mathrm{TSB}-2)$ and exponentially growing bacteria were resuspended in sterile HBSS and adjusted to $1 \times 10^{6} \mathrm{cfu}$ $\mathrm{ml}^{-1}$. Plating serial dilutions of the suspensions onto TSA-2 plates and counting the number of cfu following incubation at $22^{\circ} \mathrm{C}$ confirmed bacterial concentration of the inoculum. Plasma bactericidal activity was then determined following the method described by Graham and Secombes (25) with modifications (17).

Briefly, $20 \mu \mathrm{l}$ of plasma were added to duplicate wells of a U-shaped 96-well plate. HBSS was added to some wells instead of plasma and served as positive control. To each well, $20 \mu \mathrm{l}$ of Phdp $\left(1 \times 10^{6} \mathrm{cfu} \mathrm{ml}^{-1}\right)$ were added and the plate was incubated for $2.5 \mathrm{~h}$ at $25^{\circ} \mathrm{C} .25 \mu \mathrm{l}$ of 3-(4, 5 dimethyl-2-yl)-2,5-diphenyl tetrazolium bromide (MTT, $1 \mathrm{mg} \mathrm{ml}^{-1}$; Sigma) were then added to each well and incubated for $10 \mathrm{~min}$ at $25^{\circ} \mathrm{C}$ to allow the formation of formazan. Plates were then centrifuged at $2,000 \times g$ for $10 \mathrm{~min}$ and the precipitate was dissolved in $200 \mu \mathrm{l}$ of dimethyl sulfoxide (Sigma). The absorbance of the dissolved formazan resulting from the reduction of MTT in direct proportion to the number of viable bacteria present, was measured at $560 \mathrm{~nm}$. Viable bacteria was expressed as percentage, calculated from the difference between the dissolved formazan in samples and the one formed in the positive controls (100\%). The bactericidal activity was calculated as the percentage of non-viable bacteria.

\section{Alternative Complement Pathway Activity}

Alternative complement pathway activity (ACH50) was evaluated as described by Sunyer and Tort (26). Three buffers were previously prepared: GVB (Isotonic veronal buffered saline), pH 7.3, containing 0.1\% gelatin; EDTA-GVB, as previous one but containing $20 \mathrm{mM}$ EDTA; and Mg-EGTA-GVB, which is GVB with $10 \mathrm{mM} \mathrm{Mg}^{2+}$ and $10 \mathrm{mM}$ EGTA. Rabbit red blood cells (RaRBC; Probiologica Lda., Portugal) were washed four times in GVB and resuspended in the same buffer to a concentration of $2.5 \times 10^{8}$ cells $\mathrm{ml}^{-1}$. Then, $10 \mu \mathrm{l}$ of RaRBC suspension were added to $40 \mu \mathrm{l}$ of serially diluted plasma in Mg-EGTA-GVB buffer in triplicates. Following an incubation time of $100 \mathrm{~min}$ at room temperature with continuous shaking, the reaction was stopped by adding $150 \mu \mathrm{l}$ of cold EDTA-GVB. Samples were then centrifuged for $2.5 \mathrm{~min}$ at $120 \times \mathrm{g}$ and the extent of haemolysis was estimated by measuring the optical density of the supernatant at $414 \mathrm{~nm}$. The ACH50 units were defined as the concentration of plasma inducing 50\% haemolysis of RaRBC.

\section{Gene Expression Analysis}

Total RNA isolation was conducted with NZY Total RNA Isolation kit (NZYTech, Lisbon, Portugal) following manufacturer's specifications. First-strand cDNA was synthesized with NZY First-Strand cDNA Synthesis Kit (NZYTech, Lisbon, Portugal). Quantitative PCR assays were performed with an Eppendorf Mastercycle ep realplex, using $1 \mu \mathrm{l}$ of diluted cDNA (1:5 dilution) mixed with $10 \mu \mathrm{l}$ of NZYSpeedy qPCR Master Mix and $0.4 \mu \mathrm{l}(10 \mu \mathrm{M})$ of each specific primer in a final volume of $20 \mu \mathrm{l}$. cDNA amplification was carried out with specific primers (Table S1) for genes that have been selected for their involvement in immune responses and methionine metabolism (Table 3). Primers were designed with NCBI Primer Blast Tool according to known qPCR restrictions (amplicon size, Tm difference between primers, GC content and self-dimer or cross-dimer formation). Sequences encoding European seabass tlr2, stat 3, mtor, c3zeta, ccr 3 , mcsf1r 1 , and $c d 8 \beta$ were identified after carrying out a search in the databases v1.0c seabass genome (27) and designed 
TABLE 3 | Immune-related genes analyzed by real-time PCR.

\begin{tabular}{|c|c|c|c|}
\hline Gene & Acronym & Gene & Acronym \\
\hline $\begin{array}{l}\text { 40s Ribossomal protein } \\
\text { (House-Keeping) }\end{array}$ & $40 s$ & $\begin{array}{l}\text { Cluster of differentiation } \\
8 \text { beta }\end{array}$ & $c d 8 \beta$ \\
\hline Interleukin $1 \beta$ & $i / 1 \beta$ & Toll-like receptor 9 & $\operatorname{tr} 9$ \\
\hline Interleukin 8 & il8 & Toll-like receptor 2 & $\operatorname{tr} 2$ \\
\hline Interleukin 6 & il6 & $\begin{array}{l}\text { Macrophage } \\
\text { colony-stimulating } \\
\text { factor } 1 \text { receptor } 1\end{array}$ & mcsf1r1 \\
\hline $\begin{array}{l}\text { Transforming growth } \\
\text { factor-beta }\end{array}$ & $\operatorname{tgf} \beta$ & $\begin{array}{l}\text { Matrix- } \\
\text { metalloproteinase } \\
9\end{array}$ & mmp9 \\
\hline $\begin{array}{l}\text { Tumor necrosis } \\
\text { factor-alpha }\end{array}$ & $\operatorname{tnf} \alpha$ & Complement factor 3 & c3 \\
\hline Cyclo-oxygenase 2 & $\cos 2$ & $\begin{array}{l}\text { Mechanistic target of } \\
\text { rapamycin }\end{array}$ & mtor \\
\hline Interleukin 10 & il10 & Caspase 3 & casp 3 \\
\hline $\begin{array}{l}\text { C-C chemokine } \\
\text { receptor type } 3\end{array}$ & ccr3 & Caspase 1 & casp 1 \\
\hline $\begin{array}{l}\text { Chemokine CXC } \\
\text { receptor } 4\end{array}$ & cxcr4 & $\begin{array}{l}\text { Signal transducers and } \\
\text { activators of } \\
\text { transcription }\end{array}$ & stat 3 \\
\hline Superoxide dismutase & sod & $\begin{array}{l}\text { Melanocortin } 2 \\
\text { receptor }\end{array}$ & $m c 2 r$ \\
\hline Gutathione peroxidase & gpx & Heat shock protein 70 & hsp70 \\
\hline Hepcidin & hep & Heat shock protein 90 & hsp90 \\
\hline $\begin{array}{l}\text { Nitric oxide-inducible } \\
\text { gene protein }\end{array}$ & noxin & $\begin{array}{l}\text { Spermine/spermidine N } \\
\text { (1)-acetyltransferase }\end{array}$ & sat 1 \\
\hline $\begin{array}{l}\text { Major histocompatibility } \\
\text { complex II antigen beta } \\
\text { chain }\end{array}$ & $m h c / /$ & $\begin{array}{l}\text { Adenosylmethionine } \\
\text { decarboxylase } 1\end{array}$ & amd 1 \\
\hline $\begin{array}{l}\text { Cluster of differentiation } \\
3 \text { zeta chain }\end{array}$ & c3zeta & & \\
\hline
\end{tabular}

as previously described. $S$ was used to analyse the efficiency of the primer pairs by calculating the slope of the regression line of the cycle thresholds $(\mathrm{Ct})$ vs. the relative concentration of cDNA.

Accession number, efficiency values, annealing temperature, product length, and primers sequences are presented in Table S1. Melting curve analysis was also performed to verify that no primer dimers were amplified. The standard cycling conditions were $94^{\circ} \mathrm{C}$ initial denaturation for $2 \mathrm{~min}$, followed by 40 cycles of $94^{\circ} \mathrm{C}$ denaturation for $30 \mathrm{~s}$, primer annealing temperature (Table S1) for $30 \mathrm{~s}$ and $72^{\circ} \mathrm{C}$ extension for $30 \mathrm{~s}$. All reactions were carried out as technical duplicates. The expression of the target genes was normalized using the expression of European seabass ribosome 40 s subunit (40s).

\section{Analysis of the Peritoneal Leukocyte Populations}

Peritoneal cells were collected in fish from the time-course trial, according to the procedure described in the Peritoneal Exudates Collection section. The i.p. injected HBSS containing suspended cells was collected and total peritoneal leucocytes counts were performed with a haemocytometer. Cytospin preparations were then made with a THARMAC Cellspin apparatus and stained as indicated above for blood smears. Lymphocytes, macrophages and neutrophils in the peritoneal exudates were differentially counted, and the percentage of each cell type was established after counting a minimum of 200 cells per slide. Concentration $\left(\times 10^{4}\right.$ $\mathrm{ml}^{-1}$ ) of each leucocyte type was also calculated.

\section{Bacterial Challenge}

For the bacterial challenge, Phdp, strain PP3, isolated from yellowtail (Seriola quinqueradiata; Japan) by Dr Andrew C. Barnes (Marine Laboratory, Aberdeen, UK), was used. Bacteria were routinely cultured at $22^{\circ} \mathrm{C}$ in tryptic soy broth (TSB) or tryptic soy agar (TSA) (both from Difco Laboratories) supplemented with $\mathrm{NaCl}$ to a final concentration of $2 \%(\mathrm{w} / \mathrm{v})$ (TSB-2 and TSA-2, respectively) and stored at $-80^{\circ} \mathrm{C}$ in TSB-2 supplemented with $15 \%(\mathrm{v} / \mathrm{v})$ glycerol. To prepare the inoculum for injection into the fish peritoneal cavities, $100 \mu \mathrm{L}$ of stocked bacteria were cultured overnight at $22^{\circ} \mathrm{C}$ on TSA- 2 . Exponentially growing bacteria were collected and re-suspended in sterile TSB-2 and adjusted to a final concentration of $5 \times 10^{4}$ colony forming units (cfu) $\mathrm{ml}^{-1}$, as confirmed by plating the resulting cultures on TSA-2 plates and counting of $\mathrm{cfu}$, and each fish inoculated intraperitoneally with $100 \mu \mathrm{l}\left(5 \times 10^{3} \mathrm{cfu}\right.$ per fish) of the bacterial suspension.

\section{Data Analysis}

All results are expressed as mean \pm standard deviation (mean \pm SD). Data was analyzed for normality and homogeneity of variance and, when necessary, transformed before being treated statistically. All data expressed as percentage were arcsine transformed (28). Data was analyzed by two-way ANOVA, with time and diet as factors and followed by Tukey post-hoc test to identify differences in the experimental treatments. All statistical analyses were performed using the computer package STATISTICA 12 for WINDOWS. The level of significance used was $P \leq 0.05$ for all statistical tests. Sampling point 4 weeks was used as time $0 \mathrm{~h}$ during time-course data analysis, as they represent unstimulated animal prior to infection. The Chi-square test was performed to identify differences on the cumulative mortality among dietary treatment.

\section{RESULTS}

\section{Immune Status}

\section{Fish Growth Performance}

Thirty six fish per group (12/replicate) were sampled and weighted at 2 and 4 weeks after feeding with the experimental diets in order to evaluate the effect of the diets on the growth performance (Table 4). Within each group, no differences were found between replicate at any sampling point and between experimental diets in any of the growth parameters evaluated.

\section{Hematology and Peripheral Leucocyte Responses}

The blood of 9 fish from each group (3 per replicate), sampled at 2 and 4 weeks, was used for evaluation of hematological parameters. The hematological profile showed few changes throughout the 2-4 weeks period, with no alteration in the haematocrit. An increase of red blood cells (RBC) numbers from 2 to 4 weeks was observed within each dietary treatment, 
TABLE 4 | Data on the initial weight and growth performance of European seabass sampled at 2 and 4 weeks after being fed three different diets.

\begin{tabular}{|c|c|c|c|c|c|c|}
\hline \multirow{2}{*}{ Parameters } & \multicolumn{6}{|c|}{ Dietary treatments } \\
\hline & 2 weeks & 4 weeks & 2 weeks & 4 weeks & 2 weeks & 4 weeks \\
\hline Initial weight (g) & \multicolumn{2}{|c|}{$8.75 \pm 1.02$} & \multicolumn{2}{|c|}{$8.37 \pm 0.46$} & \multicolumn{2}{|c|}{$8.35 \pm 0.48$} \\
\hline Final weight (g) & $9.74 \pm 0.58^{*}$ & $11.43 \pm 0.33$ & $9.48 \pm 0.05^{*}$ & $11.37 \pm 0.85$ & $9.74 \pm 0.29^{\star}$ & $11.57 \pm 0.42$ \\
\hline Weight gain ${ }^{1}(\%)$ & $14.74 \pm 11.32^{*}$ & $34.74 \pm 11.68$ & $15.67 \pm 12.77^{\star}$ & $38.42 \pm 12.75$ & $13.16 \pm 5.92^{\star}$ & $42.30 \pm 10.52$ \\
\hline
\end{tabular}

TABLE 5 | Haematocrit, hemoglobin, mean corpuscular volume (MCV), mean corpuscular hemoglobin (MCH), mean corpuscular hemoglobin concentration (MCHC), red blood cells (RBC), and white blood cells (WBC) in European seabass fed dietary treatments during 2 and 4 weeks.

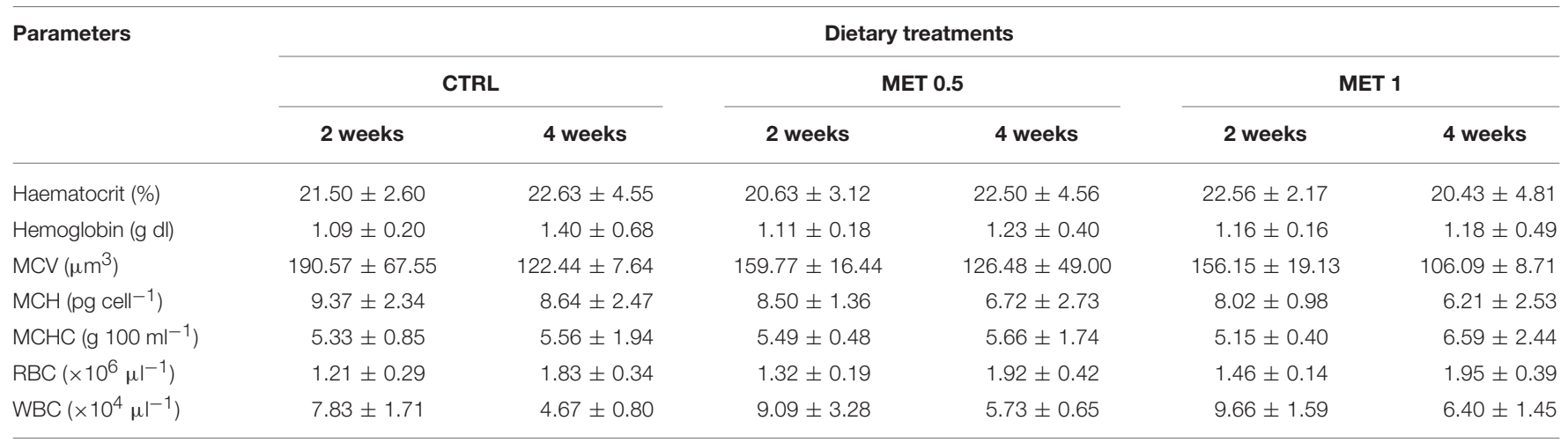

\section{Two-way ANOVA}

\begin{tabular}{lccccccc}
\hline Parameters & & & & \multicolumn{3}{c}{ Diet } \\
\cline { 5 - 7 } & Time & Diet & Time $\times$ Diet & CTRL & MET 0.5 & MET 1 \\
\hline Haematocrit & Ns & ns & ns & - & - & - \\
Hemoglobin & $n s$ & $n s$ & $n s$ & - & - & - \\
MCV & $<0.001$ & $n s$ & $n s$ & - & - & - \\
MCH & 0.032 & $n s$ & $n s$ & - & - & - \\
MCHC & $n s$ & $n s$ & $n s$ & - & - & - \\
RBC & $<0.001$ & $n s$ & $n s$ & - & - & - \\
WBC & $<0.001$ & 0.032 & $n s$ & B & AB & A
\end{tabular}

Values are presented as means $\pm S D(n=9)$. P-values from two-way ANOVA $(p \leq 0.05)$. If interaction was significant, Tukey post-hoc test was used to identify differences in the experimental treatments. Different capital letters indicate differences among diets regardless time.

although the hemoglobin $(\mathrm{Hb})$ levels have remained unaffected. With the exception of the mean corpuscular hemoglobin concentration $(\mathrm{MCHC})$, which remain unchanged between 2 and 4 weeks, all other parameters analyzed (mean corpuscular volume, MCV; mean corpuscular hemoglobin, $\mathrm{MCH}$; white blood cells, WBC) decreased from 2 to 4 weeks in each diet.

Among the different diets, and despite decreasing from 2 to 4 weeks, the WBC number was increased in the diet supplemented with $1 \%$ methionine when compared to the values observed at equivalent times for the CTRL diet (Table 5), being this increase due to a greater number of neutrophils (Table 6). In fact, with respect to the concentration of each type of leukocyte analyzed in the blood, the only difference detected between the diets was a higher number of neutrophils in the blood of the fish fed with the MET 1 diet compared to those fed with the diet CTRL and MET 0.5, but no differences were observed between 2 and 4 weeks within each group. However, for thrombocytes, lymphocytes and monocytes, although they did not vary among the fish fed the different diets, there was a decrease in their number from 2 to 4 weeks within each treatment, correlating with the decrease in WBC from 2 to 4 weeks in each diet.

Thus, while the decrease in the number of WBC from 2 to 4 weeks observed in the fish fed with each of the diets was due 
TABLE 6 | Absolute values of peripheral blood leucocytes (thrombocytes, lymphocytes, monocytes, and neutrophils) of European seabass fed dietary treatments during 2 and 4 weeks.

\begin{tabular}{|c|c|c|c|c|c|c|}
\hline \multirow[t]{2}{*}{ Parameters } & \multicolumn{6}{|c|}{ Dietary treatments } \\
\hline & 2 weeks & 4 weeks & 2 weeks & 4 weeks & 2 weeks & 4 weeks \\
\hline Thrombocytes $\left(\times 10^{4} \mu l^{-1}\right)$ & $4.16 \pm 1.05$ & $2.93 \pm 0.50$ & $4.99 \pm 2.19$ & $2.71 \pm 0.88$ & $4.68 \pm 1.03$ & $2.96 \pm 0.81$ \\
\hline Lymphocytes $\left(\times 10^{4} \mu I^{-1}\right)$ & $3.63 \pm 0.89$ & $1.58 \pm 0.40$ & $4.88 \pm 2.20$ & $2.07 \pm 0.52$ & $4.40 \pm 1.21$ & $2.52 \pm 0.91$ \\
\hline Monocytes $\left(\times 10^{4} \mu l^{-1}\right)$ & $0.23 \pm 0.08$ & $0.12 \pm 0.05$ & $0.23 \pm 0.14$ & $0.15 \pm 0.09$ & $0.25 \pm 0.10$ & $0.20 \pm 0.13$ \\
\hline
\end{tabular}

\section{Two-way ANOVA}

\begin{tabular}{lcccccc}
\hline Parameters & & & & \multicolumn{3}{c}{ Diet } \\
\cline { 5 - 7 } & Time & Diet & Time $\times$ Diet & CTRL & MET 0.5 & MET 1 \\
\hline Thrombocytes & $<0.001$ & ns & ns & - & - & - \\
Lymphocytes & $<0.001$ & ns & ns & - & - & - \\
Monocytes & 0.018 & ns & ns & - & - & - \\
Neutrophils & $n s$ & 0.004 & ns & B & B & A
\end{tabular}

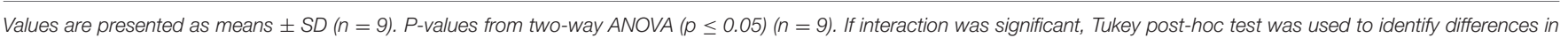
the experimental treatments. Different capital letters indicate differences among diets regardless time.

TABLE 7 | Plasma lysozyme, peroxidase, ACH50, and bactericidal activities of European seabass fed dietary treatments during 2 and 4 weeks.

\begin{tabular}{|c|c|c|c|c|c|c|}
\hline \multirow[t]{2}{*}{ Parameters } & \multicolumn{6}{|c|}{ Dietary treatments } \\
\hline & 2 weeks & 4 weeks & 2 weeks & 4 weeks & 2 weeks & 4 weeks \\
\hline Lysozyme ( $\mu \mathrm{g} \mathrm{mg} \mathrm{ml}^{-1}$ ) & $3.51 \pm 0.92^{\mathrm{a} *}$ & $1.08 \pm 0.91$ & $1.62 \pm 0.95^{b}$ & $0.89 \pm 0.61$ & $1.39 \pm 0.84^{b}$ & $0.97 \pm 0.41$ \\
\hline Peroxidase (units ml ${ }^{-1}$ ) & $124.45 \pm 32.04$ & $89.80 \pm 17.36$ & $126.56 \pm 201.13$ & $132.42 \pm 38.96$ & $129.04 \pm 48.06$ & $118.52 \pm 40.32$ \\
\hline
\end{tabular}

\section{Two-way ANOVA}

\begin{tabular}{lcccccc}
\hline Parameters & & & & \multicolumn{3}{c}{ Diet } \\
\cline { 5 - 7 } & Time & Diet & Time $\times$ Diet & CTRL & MET 0.5 & MET 1 \\
\hline Lysozyme & $<0.001$ & $<0.001$ & $<0.001$ & $\mathrm{~A}$ & $\mathrm{~A}$ & $\mathrm{~B}$ \\
Peroxidase & $\mathrm{ns}$ & $\mathrm{ns}$ & $\mathrm{ns}$ & - & - & - \\
Bactericidal activity & $<0.001$ & 0.002 & $\mathrm{~ns}$ & $\mathrm{AB}$ & $\mathrm{B}$ & $\mathrm{A}$ \\
$\mathrm{ACH} 50$ & 0.007 & $\mathrm{~ns}$ & $\mathrm{~ns}$ & - & - & -
\end{tabular}

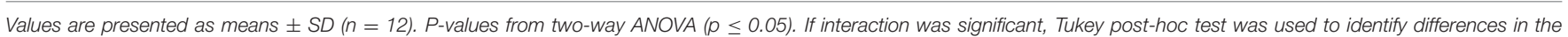

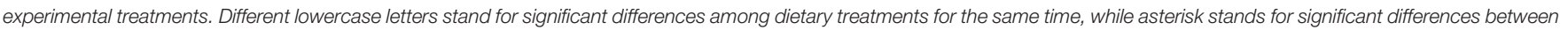
times for the same diet. Different capital letters indicate differences among diets regardless time.

to the decrease in the number of thrombocytes, monocytes and lymphocytes, the highest number of WBC observed in fish fed with the diet supplemented with $1 \%$ methionine was exclusively due to a higher number of neutrophils, suggesting the stimulation of an inflammatory response by methionine supplementation.

\section{Humoral Innate Immune Response}

For the evaluation of the innate humoral response, 36 fish were collected from each experimental group (12 per replicate) and, for reasons of quantity limitation, the plasma from each 3 fish was pooled. Humoral innate immune parameters assessed in plasma are presented in Table 7.

Two weeks after the beginning of feeding of the experimental diets, plasma of fish fed diets supplemented with methionine (MET 0.5 and MET 1) presented lower lysozyme concentration than that found in the plasma of fish fed with the control diet. Furthermore, a decrease from 2 to 4 weeks was observed in the lysozyme concentration for all diets, although only 
statistically significant for fish fed CTRL. Such decrease of lysozyme concentration could explain the reduction of the total bactericidal activity with time for all diets. Plasma bactericidal activity was found to be higher in fish fed MET 1 relative to those fed MET 0.5

Regarding the alternative complement pathway, there were no differences in activity between the different treatments, although its activity increased from 2 to 4 weeks in fish fed any of the diets.

\section{Head-Kidney Gene Expression}

To evaluate the expression of genes related to immune response and methionine metabolism role in immune response (Table 3 ), cDNA was isolated from head-kidneys collected from 9 fish from each group (3 per replicate).

High variability in the expression of many of the analyzed genes was observed, with statistically significant differences in the expression of the genes coding for IL-1b, Noxin, CD8 $\beta$, Caspase-3, Melanocortin 2 receptor, and Spermine/spermidine $\mathrm{N}$ (1)-acetyltransferase.

The normalized sat 1 expression level showed a decrease between both sampling times (Table S2). Moreover, il1 $\beta$ (Figure 2A), noxin (Figure 2B), casp3 (Figure 2C), and sat1 (Figure 2D) mRNA expression level was lower in fish fed MET 1 than in fish fed CTRL, while fish fed MET 0.5 and MET 1 presented lower $c d 8 \beta$ (Figure 2E) expression levels than fish fed CTRL dietary treatment. Fish fed MET 0.5 and Met 1 presented decreased $m c 2 r$ (Figure 2F) transcripts compared to fish fed CTRL after 2 weeks of feeding. The data regarding gene expression during the feeding trial is presented in Table S2 as Supplementary Data.

\section{Bacterial Challenge}

To evaluate a possible protective effect of a diet supplemented with methionine during a bacterial infection, 60 fish from each group (20/replicate) were inoculated with $P h d p$ and their mortality followed for 3 weeks (Figure 3 ). Fish fed any of the diets supplemented with methionine, MET0.5 and MET1, showed lower mortality than fish fed the CTRL diet, with a relative percentage survival (RPS) to fish fed the CTRL diet of 32 and $43 \%$, respectively.

Although no statistically significant differences were detected between the RPS observed between the experimental groups, this is most probably due to the fact that the number of fish per group calculated (power analysis) assuming that the supplemented diets would promote an RPS to to fish fed the CTRL diet higher than $60 \%$.

\section{Infection Response}

To examine the influence that methionine supplementation may have on the initial inflammatory response following $P h d p$ infection, samples of blood, head kidney, and peritoneal exudates were collected at 4, 24, and $48 \mathrm{~h}$ post-infection from fish of each experimental group ( 6 fish from each experimental diet by timepoint). Sampling point 4 weeks was used as time $0 \mathrm{~h}$ during timecourse data analysis, as they represent unstimulated animal prior to infection. Thus, the collected samples were used to analyze whether the diets supplemented with methionine, compared to the control diet, caused hematological alterations, influenced the innate immune response and the expression of genes in the head kidney as well as induced changes in the intraperitoneal leukocyte populations.

\section{Hematology and Peripheral Leucocyte Responses}

The concentration of RBC in the fish blood was higher at $4 \mathrm{~h}$ after infection with $P h d p$ regardless of the dietary treatment, with no effect of methionine supplementation observed, since no differences were observed between the experimental groups (Table 8). Regarding the hemoglobin concentration and the $\mathrm{MCH}$ index, no changes were observed over time within each experimental group nor between fish fed the different diets. Similarly to the RBCs, an increase in the number of WBCs in fish blood was also observed $48 \mathrm{~h}$ after infection when compared to the number of WBCs at earlier times. However, in a manner different from that observed for the concentration of RBC, it appears that methionine supplementation had an influence on the number of WBC in the blood of the fish fed with the supplemented diets, since their number is increased compared to the number of WBC in the blood of fish fed the control diet (Table 9). As already noted before infection, this increase in the number of WBC in the blood of fish fed diets supplemented with methionine seems to be due to the increase in circulating neutrophils since the number of these cells not only increases over time within any experimental group, as it is increased relative to that observed in the blood of the fish that were fed the control diet, while no differences between treatments were detected relative to the number of other leukocytes. However, within each treatment, and as observed for neutrophils, the number of thrombocytes, lymphocytes and monocytes were increased in fish blood after $48 \mathrm{~h}$ after infection compared to the time immediately before infection $(0 \mathrm{~h})$, but: (i) in the case of thrombocytes, the increase was observed at $4 \mathrm{~h}$ after infection, remaining high and without variation until $48 \mathrm{~h}$ : (ii) in the case of lymphocytes, there was a decrease in the initial times postinfection ( 4 and $24 \mathrm{~h}$ ) increasing their number at $48 \mathrm{~h}$; and (iii) in the case of monocytes, their number remained constant until $24 \mathrm{~h}$, increasing at $48 \mathrm{~h}$.

\section{Analysis of the Peritoneal Leucocytes Responses}

Total and differential peritoneal leucocytes counts were only performed in infected fish with the aim to assess cell migration dynamics to the inflammation site following bacterial injection, and are presented in Table 10. Fish fed MET 1 displayed a higher leucocyte population in the peritoneal cavity at $48 \mathrm{~h}$ than fish fed CTRL and MET 0.5, matching with the larger number of lymphocytes, macrophages and neutrophils at the same time compared to those fed with the other diets, although, due to the high variability observed in the macrophage count, no statistically significant difference was detected in the number of this type of cells. In fact, in general, an increase of all leukocyte populations over time was observed in the peritoneal cavity of fish fed the diet with higher methionine supplementation, which supports the occurrence of a stronger local inflammatory response after the intraperitoneal infection with $P h d p$ in fish fed with this diet. 


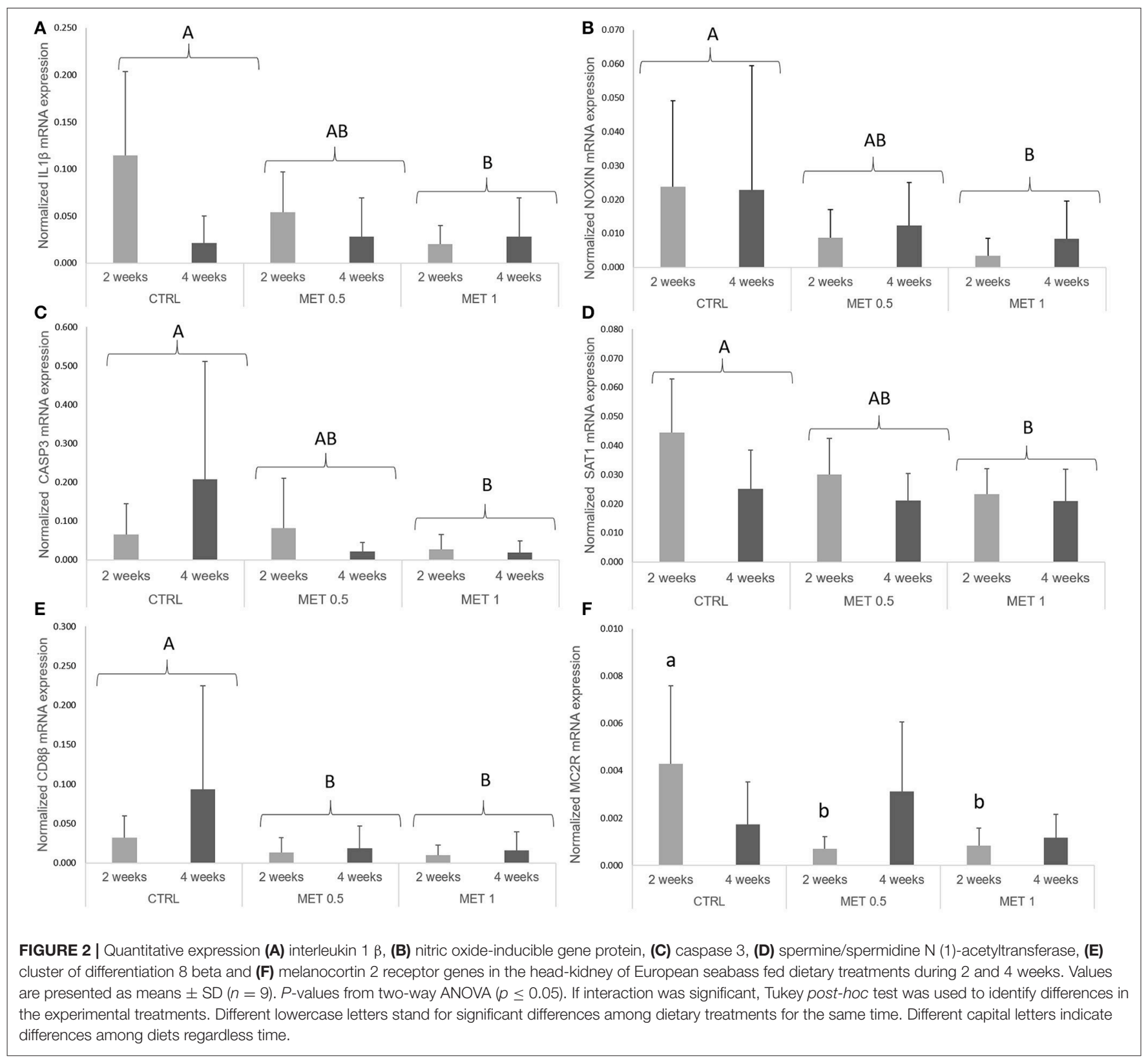

\section{Plasma Humoral Responses}

Fish fed MET 1 showed higher lysozyme activity at 24 and $48 \mathrm{~h}$ whereas fish fed MET 0.5 presented an increased activity at $48 \mathrm{~h}$ after infection compared to fish fed CTRL. Moreover, fish fed the CTRL dietary treatment showed higher lysozyme concentration at $48 \mathrm{~h}$ than at 0 and $4 \mathrm{~h}$ after infection, while fish fed MET 0.5 and MET 1 presented higher values at $24 \mathrm{~h}$ than at 4 or 0 and $4 \mathrm{~h}$, respectively (Table 11). Peroxidase activity decreased at $4 \mathrm{~h}$ compared to the other sampling points regardless dietary treatment whereas fish fed MET 0.5 showed an increased peroxidase activity compared to fish fed CTRL and MET 1 diets regardless time (Table 11). Bactericidal activity was found to increase after injection and a peak was found at $48 \mathrm{~h}$. Lastly, MET
0.5 displayed higher ACH50 levels at $24 \mathrm{~h}$ in comparison to the other dietary treatments.

\section{Head-kidney Gene Expression}

To evaluate the expression of genes related to immune response and methionine metabolism role in the inflammatory response (Table 3), cDNA was isolated from head-kidneys collected from 6 fish from each group (3 per replicate).

In response to infection with $P h d p, m m p 9$ and $\operatorname{cox} 2$ expression levels increased from 0 to $4 \mathrm{~h}$. Improved expression, relative to $0 \mathrm{~h}$ was also observed at $24 \mathrm{~h}$ for $i l 8$, casp 1 , hep, and $h s p 70$ and for $i l 10, m 2 c r$, and noxin at $48 \mathrm{~h}$. Ill $\beta$ and mtor presented improved expression at 4 and $24 \mathrm{~h}$ compared to $0 \mathrm{~h}$, whereas both $c 3$ and 

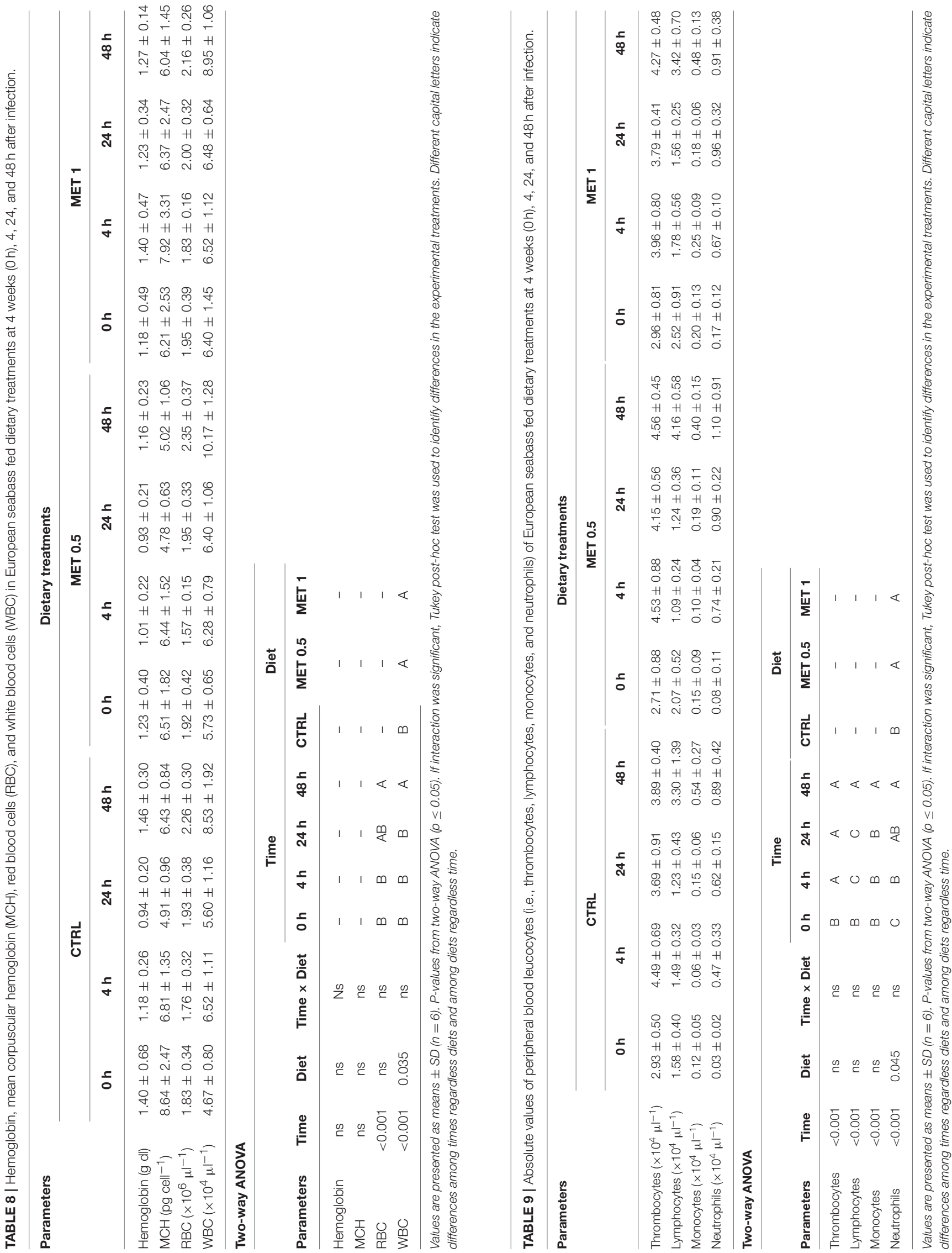

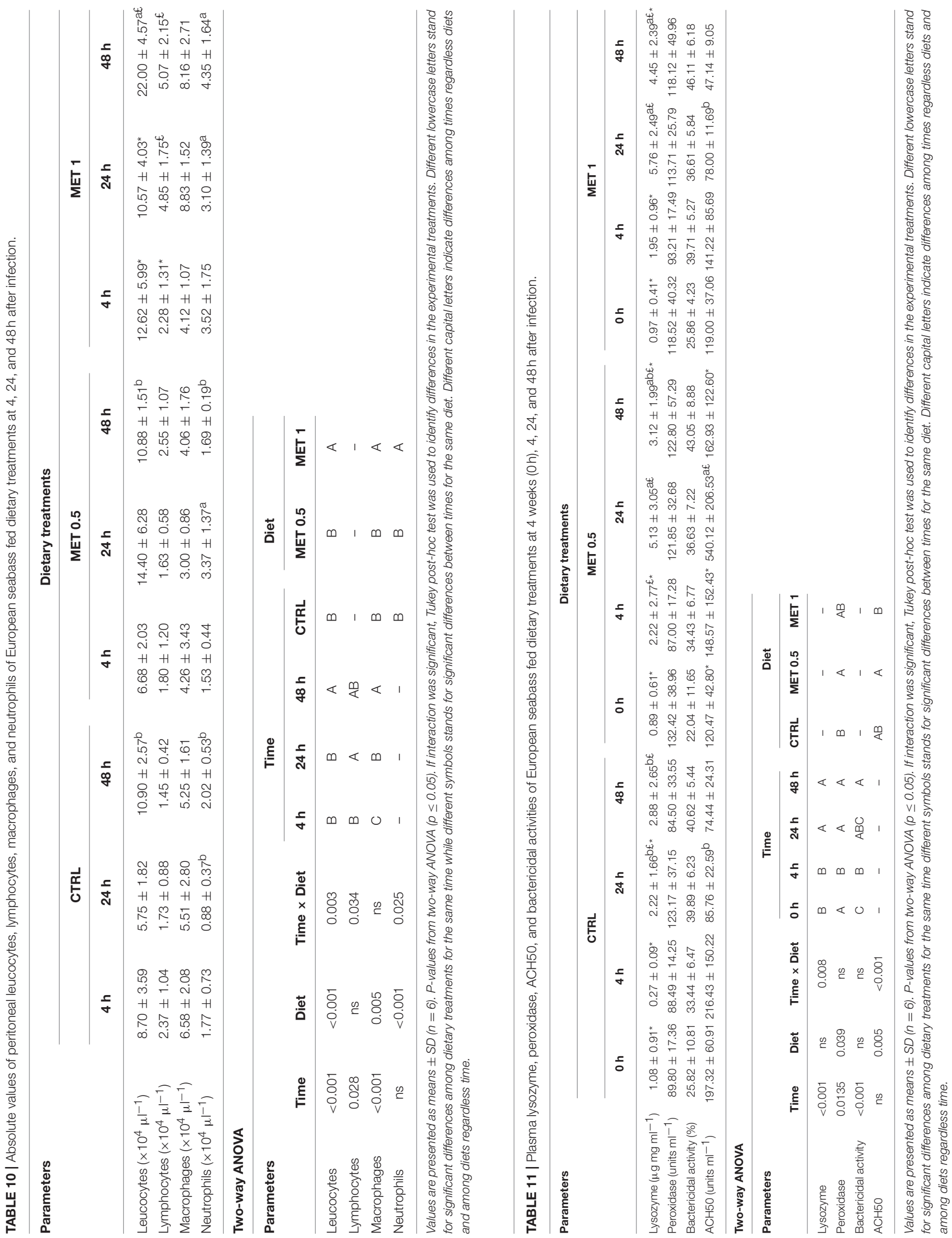
stat 3 were up-regulated at 24 and $48 \mathrm{~h}$ relative to $0 \mathrm{~h}$. At 0 and $4 \mathrm{~h}, \operatorname{tr} 9$ and $h s p 90$ expression levels were lower than at $24 \mathrm{~h}$, while $m$ hcII presented decreased values at 0 and $4 \mathrm{~h}$ relative to 24 and $48 \mathrm{~h}$ (Table S3). Both tlr2 and il6 expression levels were found higher at $24 \mathrm{~h}$ relative to 0 and $48 \mathrm{~h}$ and 0,4 , and $48 \mathrm{~h}$, respectively. Finally, noxin, cox 2 and cxcr 4 increased at $24 \mathrm{~h}$ compared to all other sampling times (Table S3).

A dietary effect was observed for casp3, as mRNA levels decreased in fish fed MET 1 compared to fish fed CTRL (Figure 4A). Moreover, mtor was found to be higher in fish fed CTRL in relation to fish fed MET 1 (Figure 4B). Fish fed MET 1 showed higher $\operatorname{tg} f \beta$ expression levels than fish fed CTRL and MET 0.5 dietary treatments at $48 \mathrm{~h}$, while an increase in time was observed for the same dietary treatment with higher levels at $48 \mathrm{~h}$ than at 0 and $4 \mathrm{~h}$ after infection (Figure 4C). Sat 1 expression level was higher in fish fed MET 1 than those fed MET 0.5 (Figure 4D), while amd1 transcripts increased in fish fed MET 1 relatively to fish fed CTRL at $4 \mathrm{~h}$. Also, fish fed MET 1 presented an improved amdl expression level at $4 \mathrm{~h}$ in comparison to all remaining times, whereas fish fed MET 0.5 increased amd1 transcripts at $4 \mathrm{~h}$ relatively to $0 \mathrm{~h}$ (Figure $4 \mathrm{E}$ ). Specifically for fish fed MET 1, tnfo mRNA expression was higher at $24 \mathrm{~h}$ than at 0 and $4 \mathrm{~h}$ (Figure 4F), while $c c r 3$ expression level augmented in fish fed MET 1 relative to fish fed CTRL at $24 \mathrm{~h}$ and also compared to the remaining times (Figure 4G). All data regarding gene expression are presented in Table S3 as Supplementary Data.

\section{DISCUSSION}

The modulatory effect of dietary methionine supplementation on the European seabass immune status was here evaluated at two different levels and for two different feeding periods. A leukopenia together with a thrombocytopenia, lymphopenia and monocytopenia was observed between the two sampling times. This cell decline was accompanied by a decrease of plasma total bactericidal activity and a reduction of spermine/spermidine N (1)-acetyltransferase (SAT1) mRNA expression, a rate-limiting enzyme involved in the regulation of the intracellular concentration of polyamines. Previous works demonstrated that methionine was able to improve the European seabass immune response in the absence of a stimulus after a 15 days feeding period by presenting higher peripheral leucocytes and neutrophils concentration, improved plasma complement levels (17) and higher head-kidney c3 mRNA expression (21). In accordance, the present study showed that methionine supplementation at the highest level led to a significant increment of total circulating leucocytes and neutrophils numbers, regardless of feeding time. Through the aminopropylation route, decarboxylated SAM, derived from methionine, is used as an aminopropyl donor to polyamine production (9). This role of methionine in polyamine synthesis may explain the enhanced leucocyte response, with a particular emphasis in neutrophils proliferation, observed in the absence of stimuli and without evidences of cell activation (e.g., neutrophils degranulation). In fact, fish fed either MET 0.5 or MET 1 dietary treatment presented a decrease in the concentration of plasmatic lysozyme after 2 weeks of feeding. This hypothesis is further supported by the down-regulation of genes encoding several proinflammatory indicators, such as the pro-inflammatory cytokine $i l 1 \beta$, the induced gene protein of nitric oxide noxin, casp 3 with central role in cell apoptosis, as well as the transmembrane glycoprotein $c d 8 \beta$ that serves as a co-receptor for the T-cell receptors. Additionally, the expression of sat1, known to be highly regulated by polyamines, was reduced by methionine supplementation which can be understood as a strategy to avoid non-specific deleterious effects in host tissues, as a negative feedback mechanism (29). Dietary methionine input is also recognized as a key factor that can increase methylation of specific genes, theoretically repressing them. DNA methylation is catalyzed by DNA methyltransferases that transfer methyl groups from SAM to cytosine in a specific cytosine-guanine $(C p G)$ and that might be enough to change gene expression. Because DNA methyltranferases reaction is dependent on the supply of SAM and the removal of S-adenosylhomocysteine $(\mathrm{SAH})$, the SAM:SAH ratio has been proposed as a "methylation ratio" (8). Moreover, Zhang (30) reviewed that due to the circular nature of methionine cycle and the complexity of the methylation reactions, the mechanisms by which methionine affects DNA methylation are poorly understood and likely to be highly dependent of tissue, animal life stage and gene region.

Methionine also plays important roles in the control of inflammatory processes, being involved in the reduction of reactive oxygen species (ROS) and protecting cells from oxidative stress through GSH metabolism (1). In the present study, the enhanced leucocyte proliferation together with lower gene expression of pro-inflammatory indicators observed at the highest methionine supplementation level tested appear to indicate that increasing methionine dietary content may improve European seabass immune status without triggering an inflammatory response. In poultry, methionine showed clear evidences of immune-stimulatory capacities, improving both humoral and cell immune responses $(16,31)$ while supplementation of dietary methionine enhanced platelet and leucocyte counts of male cotton rats (Sigmodon hispidus) (32). Besides our previous work, in which methionine-supplemented diets increased peripheral leucocytes abundance in the absence of immune stimulation (17), few more studies have focused on methionine as a health-promoting additive in aquafeeds. An increase of leucocytes concentration was observed in juvenile Jian carp fed graded levels of methionine hydroxyl analog, a synthetic methionine source, which resulted in increased survival rate after injection with Aeromonas hydrophila (18).

The enhanced immune status observed in the present study translated in a clear trend for increased disease resistance against Phdp despite the non-significant statistical result. The immune response was indeed boosted upon infection, as observed by the increased number of all peripheral leucocyte types and improved macrophages recruitment to the inflammatory focus, regardless of dietary treatment. These leucocytes migration dynamics were supported by an up-regulation of numerous pro-inflammatory genes, such as interleukins and chemokines, cell markers and receptors, transcription factors and cell stress proteins. More importantly, the enhanced immune defenses observed at the end 


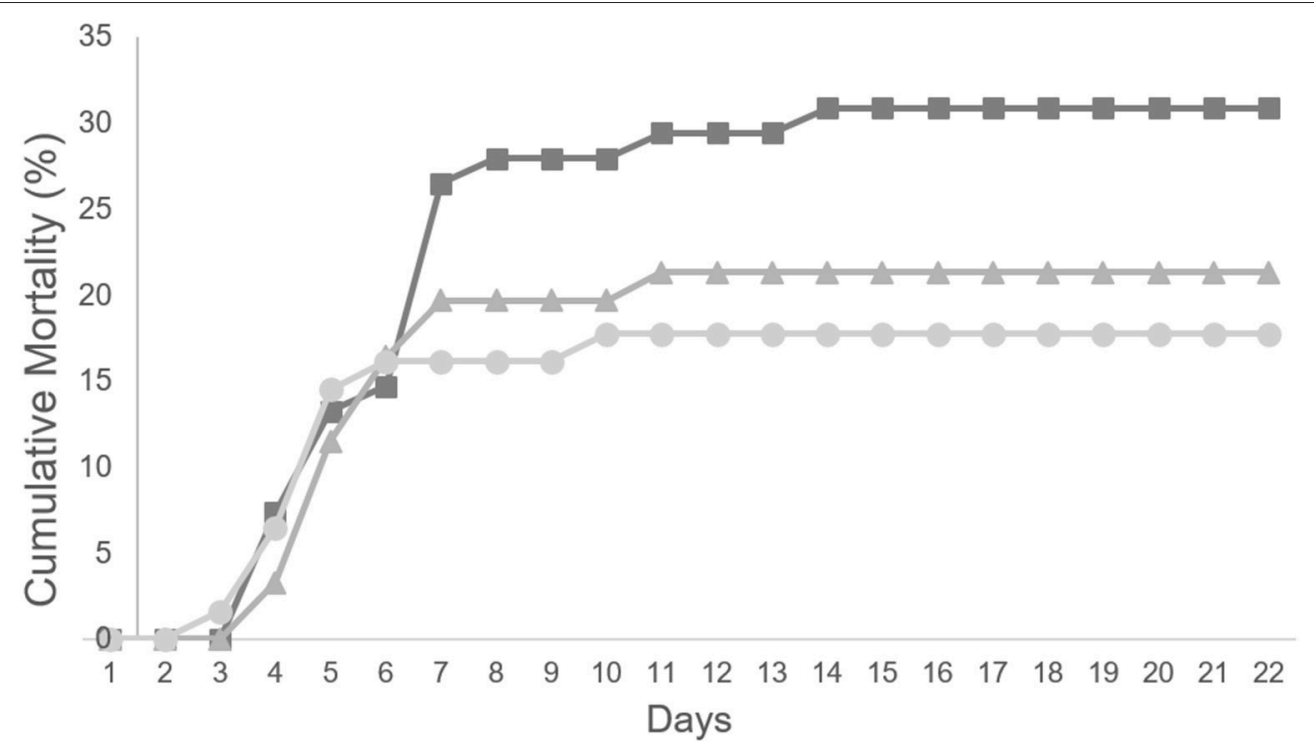

FIGURE 3 | Cumulative mortality (\%) of European seabass fed CTRL ( $)$, MET 0.5 ( $\triangle$ ) and MET $1(0)$ dietary treatments for 4 weeks and subsequently infected with Phdp $(n=60)$.

of the feeding trial in fish fed methionine-supplemented diets were triggered by infection, as similar results were observed by Machado et al. (17) for European seabass stimulated with inactivated Phdp after a 15 days feeding period, and for Jian carp (18) and juvenile yellow catfish (Pelteobagrus fulvidraco) (33) injected with Aeromonas hydrophila and fed for 60 days and 11 weeks, respectively. Similar outcomes have been reported for poultry and mammals where methionine supplementation improved chicken cellular and humoral immune mechanisms in response to Newcastle disease virus (15) and partially alleviated the depression in performance caused by aflatoxin B1 in pigs (34).

In the present study, the effect of dietary methionine supplementation seems to work in a dose-response manner in terms of cell recruitment. Indeed, fish fed MET 0.5 showed higher mobilization of neutrophils to the peritoneal cavity than fish fed CTRL dietary treatment at $24 \mathrm{~h}$, while fish fed MET 1 presented an increased concentration of leucocytes and neutrophils at the inflammatory focus compared to the other dietary groups at 24 and $48 \mathrm{~h}$. This improved cell migration dynamics is further supported by an increased number of total peritoneal leucocytes, lymphocytes and macrophages over time, which was not observed in fish fed CTRL or MET 0.5 dietary treatments. Moreover, plasma peroxidase, lysozyme and $\mathrm{ACH} 50$ activities were enhanced in general by dietary methionine surplus, probably as a result of an improved activation of phagocytic cells and better development of an inflammatory response (35), a fact also observed in previous works $(17,18)$. This improved cell-mediated response was also accompanied by sat1 up-regulation, as well as higher expression of the chemokine receptor $c c r 3$ and the multifunctional cytokine $\operatorname{tg} f \beta . c c r 3$ is a receptor for multiple inflammatory/inducible CC chemokines modulating monocytes migration and other cell types, such as NK cells and dendritic cells (36). Differently, $\operatorname{tg} f \beta$ is produced by leucocytes and is responsible for inducing transcription of different target genes related to cell differentiation, chemotaxis, proliferation, and activation of many immune cells (37). Still, a significant reduced expression of casp3, essential for processes associated with the formation of apoptotic bodies, supports the role of methionine on the control of inflammation and apoptotic mechanisms (38). mtor, regulated by nutrients [e.g., methionine (39)], energy levels, and growth factors $(40,41)$, encodes a kinase that regulates key cellular functions linked to the promotion of cell growth and metabolism. mtor mRNA levels were reduced by methionine supplementation which can be understood as a strategy to control the boosted inflammatory response described above.

The broad range of pathways in which methionine participates may have contributed to the results here described, underpinning the proposed beneficial effect of dietary methionine supplementation on seabass immune status after a 4 weeks feeding period, while improving fish response mechanisms to an infection insult. Several studies have already demonstrated the ability of dietary supplementation of specific AA in mammals (including humans) and birds to improve immune status, stress response, reducing mortality and its practical use in industry $(5,15)$. On the other hand, few works have been focused on AA dietary supplementation and fish immune mechanism $(17-19,21)$. Further studies on polyamine and cytokine protein quantification should be considered to support these hypotheses and more confidently characterize methionine role during the inflammatory response. Nonetheless, mortality results ultimately corroborate the positive effect of methionine supplementation.

In conclusion, results from the present study clearly indicate that methionine dietary supplementation could be an important nutritional startegy for fish health management 


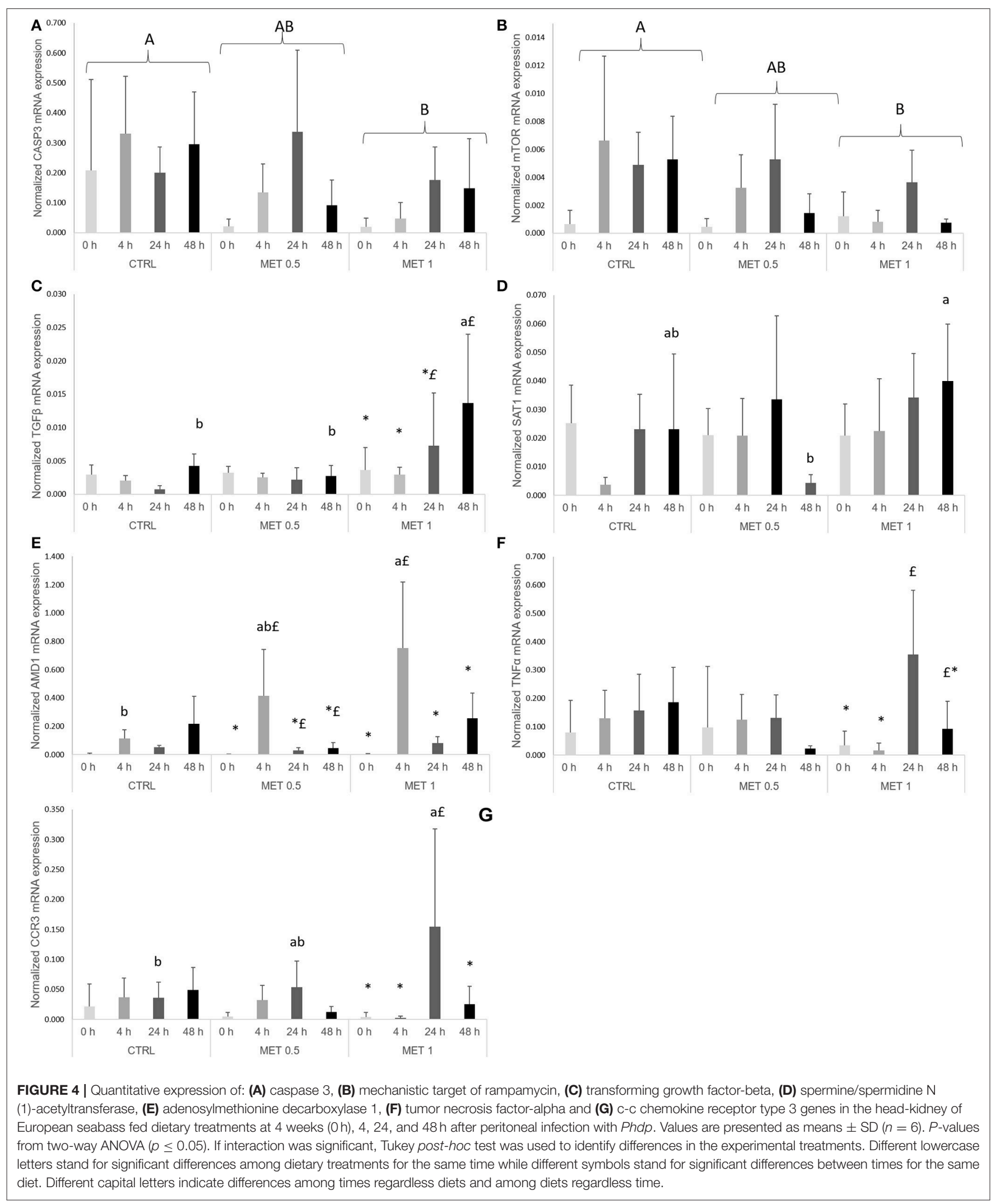


as it improved European seabass cellular immune status without triggering pro-inflammatory indicators. Furthermore, it was shown that this enhanced immune status translates into an improved inflammatory response against $P h d p$, as higher cellular differentiation/proliferation and recruitment to the inflammatory focus was observed, as well as improved plasma humoral immune parameters together with a modulation of key immune-related genes. Lastly, this work strongly suggests that dietary methionine supplementation for 4 weeks improves disease resistance against $P h d p$ in a dose-dependent manner.

\section{AUTHOR CONTRIBUTIONS}

MM, LC, and BC conceived the experiments. MM and FF conducted the experimental trial. RA and SF-B assisted with analytical procedures. MM directed most laboratory techniques and wrote the manuscript under the supervision of RA, LC, and BC. JD formulated and produced the experimental diets. All authors contributed to and approved the manuscript.

\section{REFERENCES}

1. Grimble RF, Grimble GK. Immunonutrition: role of sulfur amino acids, related amino acids, and polyamines. Nutrition (1998) 14:605-10. doi: 10.1016/S0899-9007(98)80041-5

2. Métayer S, Seiliez I, Collin A, Duchêne S, Mercier Y, Geraert P-A, et al. Mechanisms through which sulfur amino acids control protein metabolism and oxidative status. J Nutr Biochem. (2008) 19:207-15. doi: 10.1016/j.jnutbio.2007.05.006

3. Li P, Mai KS, Trushenski J, Wu GY. New developments in fish amino acid nutrition: towards functional and environmentally oriented aquafeeds. Amino Acids (2009) 37:43-53. doi: 10.1007/s00726-008-0171-1

4. Le Floc'h N, Otten W, Merlot E. Tryptophan metabolism, from nutrition to potentional therapeutic applications. Amino Acids (2011) 41:1195-205. doi: 10.1007/s00726-010-0752-7

5. Li P, Yin YL, Li D, Kim SW, Wu GY. Amino acids and immune function. Br J Nutr. (2007) 98:237-52. doi: 10.1017/S000711450769936X

6. Wu G. Amino acids: metabolism, functions, and nutrition. Amino Acids (2009) 37:1-17. doi: 10.1007/s00726-009-0269-0

7. Le Floc'h N, Melchior D, Obled C. Modifications of protein and amino acid metabolism during inflammation and immune system activation. Livestock Prod Sci. (2004) 87:37-45. doi: 10.1016/j.livprodsci.2003.09.005

8. Waterland RA. Assessing the effects of high methionine intake on DNA methylation. J Nutr. (2006) 136:1706S-10S. doi: 10.1093/jn/136.6.1706S

9. Igarashi K, Kashiwagi K. Polyamines: Mysterious modulators of cellular functions. Biochem Biophys Res Commun. (2000) 271:559-64. doi: 10.1006/bbrc.2000.2601

10. Zinngrebe J, Montinaro A, Peltzer N, Walczak H. Ubiquitin in the immune system. EMBO Rep. (2014) 15:28-45. doi: 10.1002/embr.201338025

11. Sutter BM, Wu X, Laxman S, Tu BP. Methionine inhibits autophagy and promotes growth by inducing the SAM-resoinsive methylation of PP2A. Cell (2013) 154:403-15. doi: 10.1016/j.cell.2013.06.041

12. Laxman S, Sutter BM, Tu BP. Methionine is a signal of amino acid sufficiency that inhibits autophagy through the methylation of PP2A. Autophagy (2014) 10:386-7. doi: 10.4161/auto.27485

13. Ellis AE. Immunity to bacteria to fish. Fish Shellfish Immunol. (1999) 9291308.

14. Martinez Y, Li X, Liu G, Bin P, Yan W, Mas D, et al. The role of methionine on metabolism, oxidative stress, and diseases. Amino Acids (2017) 49:2091-8. doi: 10.1007/s00726-017-2494-2

\section{ACKNOWLEDGMENTS}

This work was partially supported by Projects ALISSA (reference ALG-01-0247-FEDER-3520) and F/00197/2015, financed by Portugal and the European Union through FEDER, COMPETE 2020 and CRESC Algarve 2020, in the framework of Portugal 2020, and through the COMPETE and Operational Human Potential Programmes and national funds through Fundação para a Ciência e a Tecnologia (FCT, Portugal). MM and BC were supported by FCT, Portugal (SFRH/BD/108243/2015 and IF/00197/2015, respectively). The authors also acknowledge Dr. Nuno Santos and Dr. Ana do Vale (i3S/IBMC) support during the study and for critically reviewing the manuscript.

\section{SUPPLEMENTARY MATERIAL}

The Supplementary Material for this article can be found online at: https://www.frontiersin.org/articles/10.3389/fimmu. 2018.02672/full\#supplementary-material

15. Bunchasak C. Role of dietary methionine in poultry production. J Poultry Sci. (2009) 46:169-79. doi: 10.2141/jpsa.46.169

16. Jankowski J, Kubinska M, Zdunczyk Z. Nutritional and immunomodulatory function of methionine in poultry diets - a review. Ann Anim Sci. (2014) 14:17. doi: 10.2478/aoas-2013-0081

17. Machado M, Azeredo R, Diaz-Rosales P, Afonso A, Peres H, Oliva-Teles A, et al. Dietary tryptophan and methionine as modulators of European seabass (Dicentrarchus labrax) immune status and inflammatory response. Fish Shellfish Immunol. (2015) 42:353-62. doi: 10.1016/j.fsi.2014.11.024

18. Kuang SY, Xiao WW, Feng L, Liu Y, Jiang J, Jiang WD, et al. Effects of graded levels of dietary methionine hydroxy analogue on immune response and antioxidant status of immune organs in juvenile Jian carp (Cyprinus carpio var. Jian). Fish Shellfish Immunol. (2012) 32:629-36. doi: 10.1016/j.fsi.2011.12.012

19. Tang L, Wang GX, Jiang J, Feng L, Yang L, Li SH, et al. Effect of methionine on intestinal enzymes activities, microflora and humoral immune of juvenile Jian carp (Cyprinus carpio var. Jian). Aquacult Nutr. (2009) 15:477-83. doi: 10.1111/j.1365-2095.2008.00613.x

20. Kaushik SJ. Whole body amino acid composition of European seabass (Dicentrarchus labrax), gilthead seabream (Sparus aurata) and turbot (Psetta maxima) with an estimation of their IAA requirement profiles. Aquatic Living Res. (1998) 11:355-8. doi: 10.1016/S0990-7440(98)80007-7

21. Azeredo R, Machado M, Afonso A, Fierro-Castro C, Reyes-Lopez FE, Tort L, et al. Neuroendocrine and immune responses undertake different fates following tryptophan or methionine dietary treatment: tales from a Teleost model. Front Immunol. (2017) 8:1226. doi: 10.3389/fimmu.2017.01226

22. Costas B, Conceicao LEC, Dias J, Novoa B, Figueras A, Afonso A. Dietary arginine and repeated handling increase disease resistance and modulate innate immune mechanisms of Senegalese sole (Solea senegalensis Kaup, 1858). Fish Shellfish Immunol. (2011) 31:838-47. doi: 10.1016/j.fsi.2011.07.024

23. Afonso A, Silva J, Lousada S, Ellis AE, Silva MT. Uptake of neutrophils and neutrophilic components by macrophages in the inflamed peritoneal cavity of rainbow trout (Oncorhynchus mykiss). Fish Shellfish Immunol. (1998) 8:319-38. doi: 10.1006/fsim.1998.0139

24. Quade MJ, Roth JA. A rapid, direct assay to measure degranulation of bovine neutrophil primary granules. Vet Immunol Immunopathol. (1997) 58:239-48. doi: 10.1016/S0165-2427(97)00048-2

25. Graham S, Secombes CJ. The production of a macrophage-activating factor from rainbow-trout Salmo-Gairdneri leukocytes. Immunology (1988) 65:293-7. 
26. Sunyer JO, Tort L. Natural hemolytic and bactericidal activities of sea bream sparus-aurata serum are effected by the alternative complement pathway. Vet Immunol Immunopathol. (1995) 45:333-45. doi: 10.1016/0165-2427(94)05430-Z

27. Tine M, Kuhl H, Gagnaire PA, Louro B, Desmarais E, Martins RS, et al. European sea bass genome and its variation provide insights into adaptation to euryhalinity and speciation. Nat Commun. (2014) 5:5770. doi: $10.1038 /$ ncomms6770

28. Zar JH. Biostatistical Analysis. Pearson (1999), p. 478-81.

29. Pegg AE. Spermidine/spermine-N(1)-acetyltransferase: a key metabolic regulator. Am J Physiol Endocrinol Metab. (2008) 294:E995-1010. doi: 10.1152/ajpendo.90217.2008

30. Zhang N. Role of methionine on epigenetic modification of DNA methylation and gene expression in animals. Anim Nutr. (2017) 4:11-16. doi: 10.1016/j.aninu.2017.08.009

31. Tsiagbe VK, Cook ME, Harper AE, Sunde ML. Enhanced immune-responses in broiler chicks fed methionine-supplemented diets. Poult Sci. (1987) 66:1147-54. doi: 10.3382/ps.0661147

32. Webb RE, Leslie DM, Lochmiller RL, Masters RE. Immune function and hematology of male cotton rats (Sigmodon hispidus) in response to food supplementation and methionine. Comp Biochem Physiol A Mol Integr Physiol. (2003) 136:577-89. doi: 10.1016/s1095-6433(03)00209-5

33. Elmada CZ, Huang W, Jin M, Liang X, Mai K, Zhou Q. The effect of dietary methionine on growth, antioxidant capacity, innate immune response and disease resistance of juvenile yellow catfish (Pelteobagrus fulvidraco). Aquacult Nutr. (2016) 22:1163-73. doi: 10.1111/anu.12363

34. Coffey MT, Hagler JWM, Cullen JM. Influence of dietary protein, fat or amino acids on the response of weanling swine to aflatoxin B13. J Anim Sci. (1989) 67:465-72. doi: 10.2527/jas1989.672465x
35. Faurschou M, Borregaard N. Neutrophil granules and secretory vesicles in inflammation. Microbes Infect. (2003) 5:1317-27. doi: 10.1016/j.micinf.2003.09.008

36. Mélik-Parsadaniantz S, Rostène W. Chemokines and neuromodulation. J Neuroimmunol. (2008) 198:62-8. doi: 10.1016/j.jneuroim.2008.04.022

37. Massagué J. TGF $\beta$ signalling in context. Nat Rev Mol Cell Biol. (2012) 13:61630. doi: $10.1038 / \mathrm{nrm} 3434$

38. Porter AG, Janicke RU. Emerging roles of caspase-3 in apoptosis. Cell Death Differ. (1999) 6:99-104. doi: 10.1038/sj.cdd.4400476

39. Zhou Y, Ren J, Song T, Peng J, Wei H. Methionine regulates mTORC1 via the T1R1/T1R3-PLC $\beta-\mathrm{Ca}(2+)$-ERK1/2 signal transduction process in $\mathrm{C} 2 \mathrm{C} 12$ cells. Int J Mol Sci. (2016) 17:1684. doi: 10.3390/ijms17101684

40. Wang X, Campbell LE, Miller CM, Proud CG. Amino acid availability regulates p70 S6 kinase and multiple translation factors. Biochem J. (1998) 334(Pt 1):261-7.

41. Betz C, Hall MN. Where is mTOR and what is it doing there? J Cell Biol. (2013) 203:563-74. doi: 10.1083/jcb.201306041

Conflict of Interest Statement: The authors declare that the research was conducted in the absence of any commercial or financial relationships that could be construed as a potential conflict of interest.

Copyright (C) 2018 Machado, Azeredo, Fontinha, Fernández-Boo, Conceição, Dias and Costas. This is an open-access article distributed under the terms of the Creative Commons Attribution License (CC BY). The use, distribution or reproduction in other forums is permitted, provided the original author(s) and the copyright owner(s) are credited and that the original publication in this journal is cited, in accordance with accepted academic practice. No use, distribution or reproduction is permitted which does not comply with these terms. 